\section{Kidney \\ Blood Pressure Research}

Kidney Blood Press Res 2012;36:301-309

\begin{tabular}{l|l}
\hline DOI: $10.1159 / 000343419$ & C) 2012 S. Karger AG, Basel
\end{tabular}

www.karger.com/kbr

301

Original Paper

\title{
Autosomal Dominant Polycystic Kidney Disease and Hypertension are Associated with Left Ventricular Mass in a Gender- Dependent Manner
}

\author{
Maria Pietrzak-Nowacka ${ }^{\mathrm{a}} \quad$ Krzysztof Safranow $^{\mathrm{b}} \quad$ Małgorzata Czechowskac $^{\mathrm{c}}$ \\ Grażyna Dutkiewicza Zdzisława Kornacewicz-Jachc Kazimierz Ciechanowskia \\ aDepartment of Nephrology, Transplantology and Internal Medicine, Pomeranian Medical University, \\ Szczecin, Poland, 'Department of Biochemistry and Medical Chemistry, Pomeranian Medical University, \\ Szczecin, Poland, 'Department of Cardiology, Pomeranian Medical University, Szczecin, Poland
}

\section{Key Words}

Autosomal-dominant polycystic kidney disease - Gender - Hypertension • Left ventricular hypertrophy $\cdot$ Normal renal function

\begin{abstract}
Background: The aim of this study was to compare echocardiographic parameters in patients with autosomal dominant polycystic kidney disease (ADPKD) and in controls with normal kidney function taking into account gender and the presence of hypertension. Methods: 47 patients with ADPKD (age $36.3 \pm 11.0$ years) and 49 healthy controls (36.8 \pm 9.2 years) were enrolled. M-mode echocardiography was performed in all subjects. Left ventricular hypertrophy (LVH) was diagnosed when the left ventricular mass index (LVMI) was greater than or equal to $125 \mathrm{~g} / \mathrm{m}^{2}$ in males and $110 \mathrm{~g} / \mathrm{m}^{2}$ in females. Results: The prevalence of LVH was greater in ADPKD patients than in controls ( $13 \%$ vs $2 \% ; p=0.05$ ). Among females, ADPKD patients demonstrated greater LVMI $\left(87.9 \pm 18.5\right.$ vs $\left.68.8 \pm 15 \mathrm{~g} / \mathrm{m}^{2}, \mathrm{p}=0.00009\right)$ than controls. There was a positive correlation between LVMI and blood pressure in ADPKD females (Rs $=0.54$, $p=0.027$ for systole blood pressure-SBP and $R s=0.50, p=0.0053$ for diastole blood pressureDBP) but not in males. Conclusion: Left ventricular mass is increased in ADPKD females with normal renal function. A positive correlation between SBP and DBP and LVMI was found in ADPKD females but not in ADPKD males.
\end{abstract}




\section{Kidney \\ Blood Pressure Research}

Kidney Blood Press Res 2012;36:301-309

\begin{tabular}{l|l}
\hline DOI: $10.1159 / 000343419$ & (C) 2012 S. Karger AG, Basel
\end{tabular}

Published online: December 12, 2012

www.karger.com/kbr

with LVM

\section{Introduction}

Autosomal dominant polycystic kidney disease (ADPKD) is the most commonly diagnosed inherited kidney defect with the prevalence of 1:400-1:1000 among Caucasians. ADPKD proves to be equally widespread among all races [1]. In the developed countries, $4-10 \%$ of the total number of the hemodialysed individuals are patients with ADPKD [2]. Total body involvement is observed in the disease, with extrarenal localization of the cysts in the liver (94\%), seminal vesicles (40\%), and pancreas $(9 \%)$, as well with connective tissue abnormalities such as mitral valve prolapse $(25 \%)$, intracranial aneurysms $(8 \%)$, and abdominal hernia (10\%) [3].

Arterial hypertension (HT) is observed in approximately half of ADPKD patients. HT often precedes impairment of kidney function [4] and its prevalence is notably higher in males [5]. De Almeida et al. found that ambulant systolic and diastolic blood pressures (SBP, DBP) were significantly higher in young normotensive ADPKD-diagnosed individuals than in age- and gender-matched controls [6]. Valero et al. [7] reported that the nocturnal blood pressure dip was attenuated in normotensive patients with ADPKD. Martinez-Vea at al. disclosed a greater prevalence of left ventricular hypertrophy (LVH) in hypertensive ADPKD patients than in the general population [8].

Factors contributing to LVH in ADPKD include older age, elevated serum creatinine and uric acid levels, increased mean arterial blood pressure, and longer history of hypertension $[9,10]$. Bardaji et al. showed that hypertensive ADPKD subjects demonstrate an increase in left ventricular mass (LVM) correlating with loss of renal function [11]. MRI assessment in hypertensive ADPKD patients with normal renal function (GFR $>60 \mathrm{ml} / \mathrm{min} / 1.73 \mathrm{~m}^{2}$ ) by Perrone et al. revealed significant associations of the left ventricular mass index (LVMI) with SBP, serum creatinine, and albuminuria. Higher LVMI was also significantly associated with older age and male gender [12]. Other studies in normotensive young adults with ADPKD and normal renal function found increased LVMI, impaired biventricular diastolic function, prolonged isovolumetric relaxation time (IVRT), endothelial dysfunction, increased carotid intima-media thickness, and reduced coronary flow velocity [13-15].

The present study was undertaken to compare M-mode echocardiographic parameters in ADPKD-diagnosed patients with normal kidney function and in controls without renal failure taking into account gender and hypertension.

\section{Patients and Methods}

Forty-seven adult, ADPKD-diagnosed patients (29 females and 18 males), aged 18 to 61 years, were enrolled, while the control group comprised 49 gender and age-matched healthy individuals (28 females and 21 males) specifically recruited for this study. The inclusion criteria for the ADPKD group were as follows: presence of cysts in both kidneys, allowing a diagnosis of PKD according to Ravine et al. [16], a family history of ADPKD. Exclusion criteria were: serum creatinine $\geq 1.35 \mathrm{mg} / \mathrm{dL}$, and a positive history of diabetes. As controls, individuals with a negative family history of ADPKD, absence of cysts in the kidneys (Ravines criteria not fulfilled), a serum creatinine $\leq 1.35 \mathrm{mg} / \mathrm{dL}$ and no prior diagnosis of diabetes. Each participating individual was thoroughly informed about the study methods and objectives and personally granted his/her written consent to participate in the study. The study protocol was approved by the Ethical Committee of the Pomeranian Medical University, Szczecin, Poland (approval No.001/135/06).

At the start of the study, morphometric parameters were recorded (body mass, height, waist and hip circumferences) and the body mass index (BMI) and the waist-to-hip ratio (WHR) were calculated. The estimated glomerular filtration rate (eGFR) was based on a single serum creatinine measurement. The Chronic Kidney Disease Epidemiology Collaboration (CKD-EPI) formula was used [17].

Blood pressure was measured three times on different days in the left arm using a standard mercury sphygmomanometer, in the sitting position, after a 10 minute rest with a mean value used in analyses. Hypertension was defined as the use of a hypertensive medication or systolic/diastolic blood pressure $\geq 140 / 90 \mathrm{mmHg}$. 


\section{Kidney Blood Pressure Research}

Kidney Blood Press Res 2012;36:301-309

\begin{tabular}{l|l}
\hline DOI: $10.1159 / 000343419$ & (C) 2012 S. Karger AG, Basel
\end{tabular}

Published online: December 12, 2012

www.karger.com/kbr

Pietrzak-Nowacka/Safranow/Czechowska et al.: ADPKD and Hypertension are Associated with LVM

Standard two-dimensional and two-dimensionally guided M-mode echocardiography (General Electric Vivid 7 system, 3.5 MHz transducer) was done by the same sonographer blinded to the diagnostic category. Two-dimensionally guided M-mode echocardiograms were performed according to the American Society of Echocardiography Guidelines. The left ventricular end-diastolic diameter (LVEDd), interventricular septal end-diastolic dimension (IVSd), left ventricular end-diastolic posterior wall dimension (LVPWd), aortic root dimension (AO), and left atrial dimension (LA) were measured. The left ventricular ejection fraction (LVEF) was estimated with Simpson's method.

Two-dimensional studies comprised the parasternal long-axis and short-axis, apical four-chamber, apical long-axis two-chamber, and subcostal views. Estimates of LVM were based on the American Society of Echocardiography convention with the Devereux correction according to the following formula:

$\operatorname{LVM}(\mathrm{g})=0.8 \times 1.04\left((\mathrm{LVEDd}+\mathrm{IVSd}+\mathrm{LVPWd})^{3}-\mathrm{LVEDd}^{3}\right)+0.6$

LVH was diagnosed when LVMI was greater than or equal to $125 \mathrm{~g} / \mathrm{m}^{2}$ in males and $110 \mathrm{~g} / \mathrm{m}^{2}$ in females.

The Mann-Whitney test and Fisher's exact test were used for the statistical analysis of quantitative and qualitative variables, respectively. Data are presented as number (percentage) for qualitative variables or mean \pm standard deviation for quantitative variables. Correlations between quantitative variables were studied with Spearman's rank correlation coefficient (Rs). The level of significance was taken as p $<0.05$. Computations were done with Statistica 7.1 software.

\section{Results}

Anthropometric, clinical, and biochemical data of the ADPKD and control groups stratified by gender are presented in Table 1 . The age and gender distribution in both groups was similar. No significant differences between ADPKD-diagnosed patients and controls were found for anthropometric values such as BMI and BSA. It must be noted that WHR was significantly higher in the ADPKD group compared to controls for females but not for males. Moreover, SBP and DBP values were significantly higher in the ADPKD group (SBP only for females). eGFR did not differ significantly between the groups and genders. Hypertension was significantly more frequent in the ADPKD group for both genders and within the ADPKD group it was more frequent in males compared to females.

M-mode echo data of ADPKD patients and controls stratified by gender are presented in Table 2. In the control group, males demonstrated significantly higher LVEDd, LVPWd, IVSd, AO, LA, and LVMI in comparison to females. In the ADPKD group, LVEDd, LVPWd AO and LA were significantly higher in males than females. ADPKD females demonstrated significantly higher LVEDd, LVPWd, IVSd, AO, LA, and LVMI than control females. AO was significantly higher in ADPKD males than male controls. The prevalence of LVH in ADPKD patients was slightly higher in comparison to controls (all: $13 \%$ vs $2 \%, p=0.057$; females: $10 \%$ vs $4 \%$, $\mathrm{p}=0.61$; males: $17 \%$ vs $0 \%, \mathrm{p}=0.089$ ).

Echo data and blood pressure values for ADPKD patients and controls stratified according to the presence of hypertension are presented in Table 3 (females) and Table 4 (males). NonHT ADPKD females demonstrated statistically higher LVEDd, IVSd, AO, LVMI, and DBP than non-HT female controls. In the ADPKD group, IVSd, LVMI, and SBP were significantly higher in HT than non-HT females. ADPKD females with HT compared with female non-HT controls showed significantly higher values of all parameters except LVEF.

Small group of ADPKD non-HT males $(n=4)$ demonstrated significantly lower IVSd values in comparison to both non-HT ADPKD males and non-HT control males. ADPKD males with HT demonstrated significantly higher AO, LA, and DBP than non-HT male controls.

Correlations of blood pressure values and echocardiographic data in ADPKD patients and controls stratified by gender are presented in Table 5 and Figure 1 . In control females, SBP correlated positively with LVPWd, AO and LA, whereas DBP correlated with LVPWd and LVMI. In control males, DBP correlated positively with LA, whereas LVEF correlated negatively with SBP and DBP. In ADPKD females, SBP and DBP correlated with LVPWd, IVSd, $\mathrm{AO}$, and LVMI. In ADPKD males, SBP and DBP correlated positively with LVEDd. 


\section{Kidney \\ Blood Pressure Research}
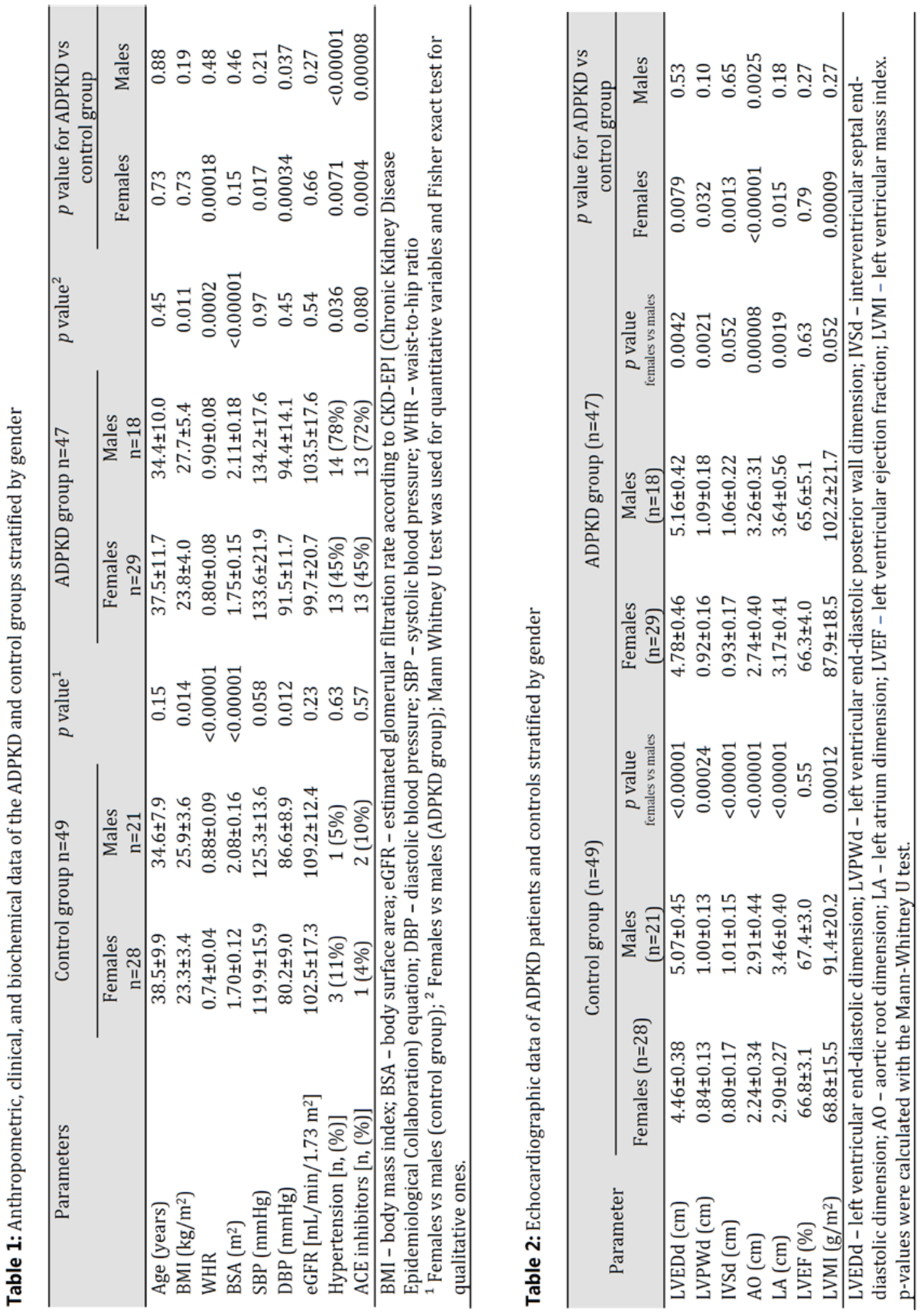

\section{Discussion}

Our echocardiographic data showed gender differences described for the general population $[18,19]$. Greater prevalence of HT among ADPKD males than females has already 


\section{Kidney \\ Blood Pressure Research}

Fig. 1. Correlations of systolic blood pressure (SBP) with left ventricular mass index (LVMI) in ADPKD males and females.

Pietrzak-Nowacka/Safranow/Czechowska et al.: ADPKD and Hypertension are Associated with LVM

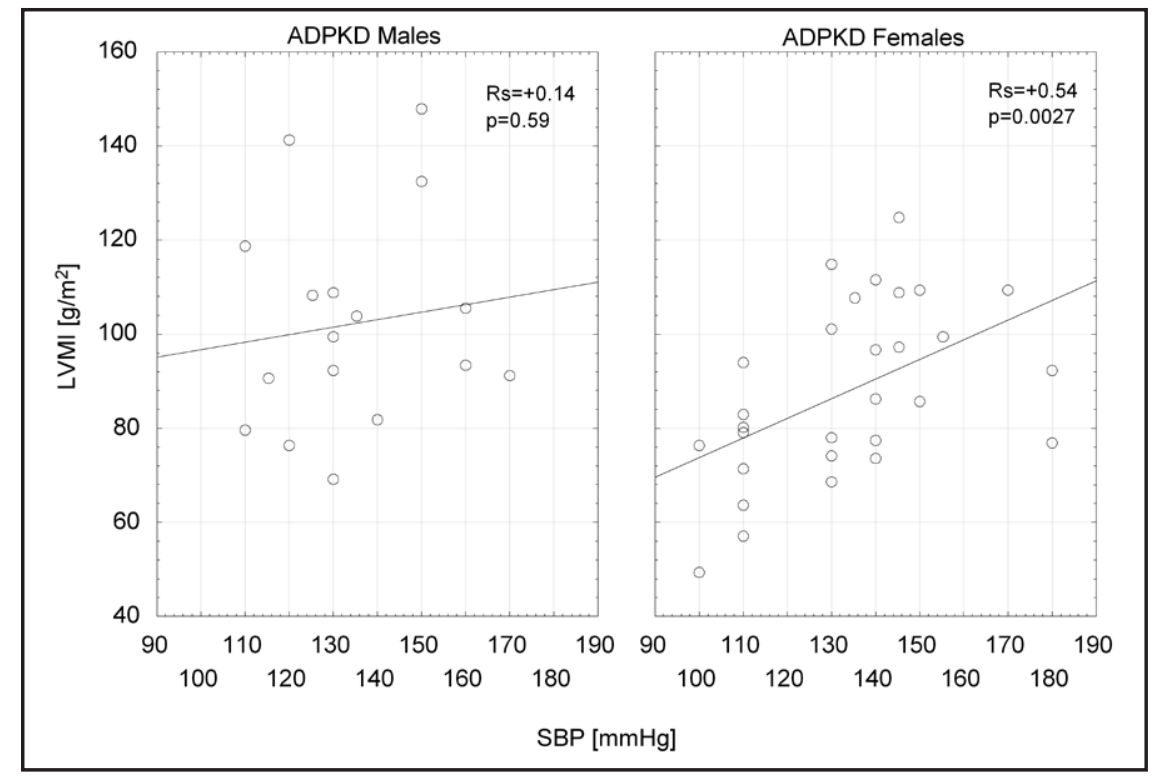

been reported [5]. We showed also that arterial hypertension occurred more frequently among males than females in ADPKD group (Table 1). We observed increased LVMI in nonHT ADPKD females in comparison to non-HT control females. These results are in agreement with Bardaji et al. [14] who found higher LVMI in non-HT ADPKD females and males with normal renal function.

Bardaji et al. [14] reported that LVMI correlated with SBP in ADPKD patients $(\mathrm{R}=0.36$, $\mathrm{p}=0.01)$ and controls $(\mathrm{R}=0.43, \mathrm{p}=0.006)$. No correlation between LVM and DBP was found in the ADPKD and control groups. We found that LVMI correlated with SBP and DBP in ADPKD females. Bardaji et al. [14] reported also that young normotensive patients with ADPKD revealed LVMI and Doppler abnormalities consistent with early diastolic dysfunction but they could not show a correlation between LVM and deceleration time or isovolumetric relaxation time in either group. Martinez-Vea et al. [15] showed that young normotensive patients with ADPKD had increased LVMI and presented with Doppler abnormalities consistent with early diastolic dysfunction. In the present study we did not analyze left ventricular diastolic function.

Arterial hypertension is an important hemodynamic risk factor for LVH [8] in ADPKD patients like in the general population [20]. It is well known that the prevalence of left ventricular hypertrophy in the general population is related to blood pressure and occurs less often in females than males even though left ventricular mass correlates with body surface area or body mass [21]. In our study, ADPKD females demonstrated smaller BMI and BSA than males. Age of females and males was similar. Hypertension in ADPKD patients has some specific features which may be responsible for earlier onset of LVH: HT is often diagnosed before any substantial reduction in the glomerular filtration rate and patients present with higher SBP, DBP and a lower nocturnal dip in blood pressure in comparison to hypertensives in the general population [7].

We disclosed LVH, using echocardiography, in 19\% of HT ADPKD patients with normal renal function. In the HALT PKD study measurements were performed using cardiac magnetic resonance (MR) in 543 hypertensive ADPKD patients $<50$ years with short duration of HT and prior use of ACE inhibitors/angiotensin receptor blockers, with normal renal function (GFR $>60 \mathrm{ml} / \mathrm{min} / 1.72 \mathrm{~m}^{2}$ ) [12]. The prevalence of LVH (cardiac MR LVMI $>106.2 \mathrm{~g} / \mathrm{m}^{2}$ in males, $>84.6 \mathrm{~g} / \mathrm{m}^{2}$ in females) was unexpectedly low: $0.93 \%$. The authors suggest that this phenomenon might be caused by aggressive HT treatment in their cohort of patients. The difference in LVH prevalence between females and males was not statistically significant [12]. Similarly, in our study the frequency of LVH was not significantly different in females and males with ADPKD (17\% vs $10 \%, \mathrm{p}=0.66)$. 


\section{Kidney \\ Blood Pressure Research}
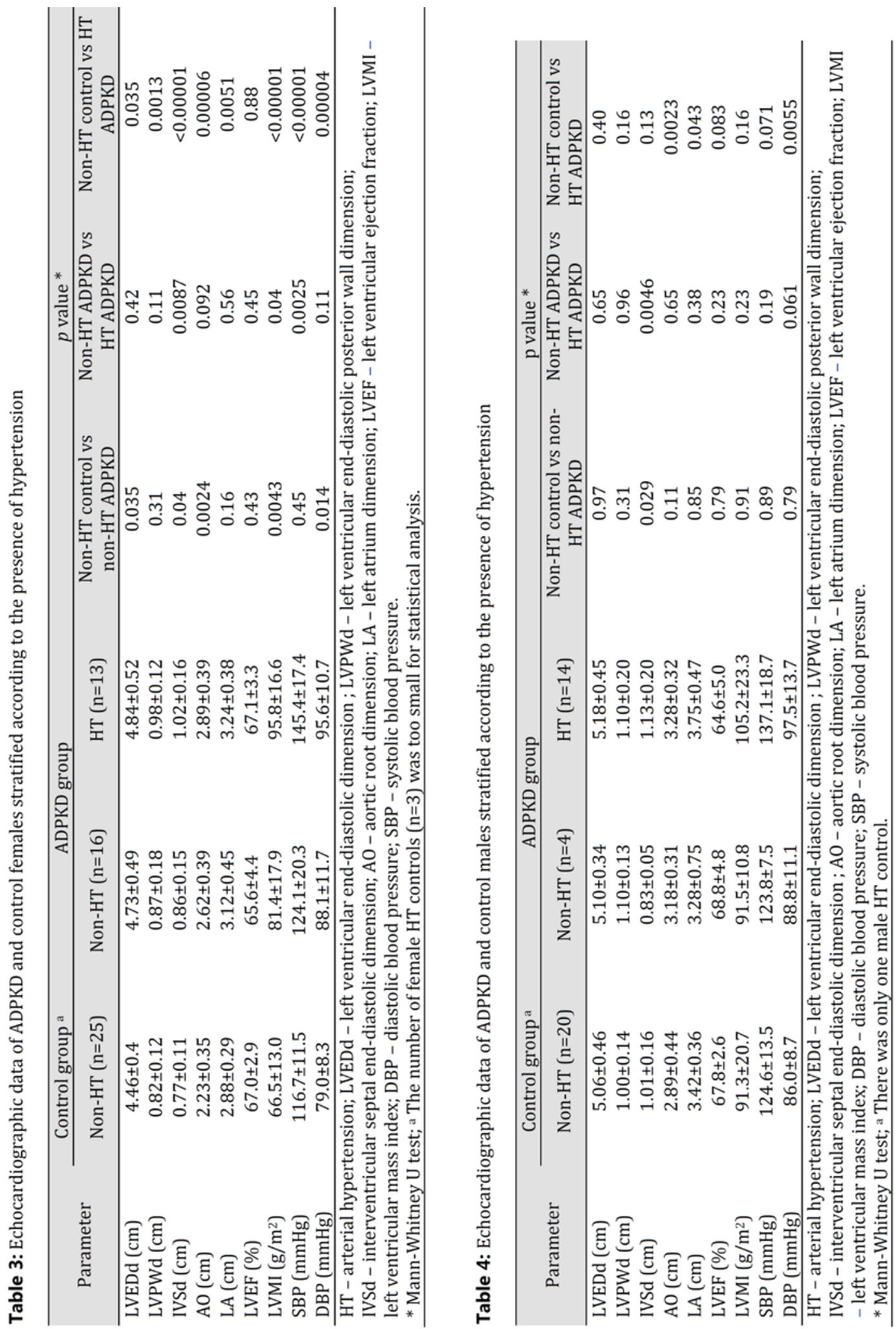

Chapman et al. [9] compared the prevalence of LVH (LVMI $>125 \mathrm{~g} / \mathrm{m}^{2}$ for males, LVMI $>110 \mathrm{~g} / \mathrm{m}^{2}$ for females) between ADPKD patients and controls and found it to be greater in ADPKD males ( 46 vs $20 \%, \mathrm{p}<0.05$ ) and females (37 vs $12 \%, \mathrm{p}<0.005$ ). The hypertensive ADPKD patients with $\mathrm{LVH}$ had greater serum creatinine concentrations than subjects 


\section{Kidney \\ Blood Pressure Research}

Kidney Blood Press Res 2012;36:301-309

\begin{tabular}{l|l}
\hline DOI: $10.1159 / 000343419$ & (C) 2012 S. Karger AG, Basel
\end{tabular}

Published online: December 12, 2012

www.karger.com/kbr

Pietrzak-Nowacka/Safranow/Czechowska et al.: ADPKD and Hypertension are Associated with LVM

Table 5: Correlations of blood pressure values and echocardiographic data in ADPKD patients and controls stratified by gender. Spearman's rank correlations coefficients (Rs) and corresponding $\mathrm{p}$ values are presented.

\begin{tabular}{|c|c|c|c|c|c|c|c|c|}
\hline \multirow{2}{*}{ Parameters } & \multicolumn{2}{|c|}{ SBP } & \multicolumn{2}{|c|}{ DBP } & \multicolumn{2}{|c|}{ SBP } & \multicolumn{2}{|c|}{ DBP } \\
\hline & Rs & $\mathrm{p}$ & Rs & $\mathrm{p}$ & Rs & $\mathrm{p}$ & Rs & $\mathrm{p}$ \\
\hline & \multicolumn{8}{|c|}{ Control group $(n=49)$} \\
\hline & \multicolumn{4}{|c|}{ Females $(n=28)$} & \multicolumn{4}{|c|}{ Males (n=21) } \\
\hline LVEDd (cm) & +0.03 & 0.89 & -0.11 & 0.58 & +0.14 & 0.54 & +0.35 & 0.11 \\
\hline LVPWd $(\mathrm{cm})$ & +0.46 & 0.013 & +0.67 & $<0.0001$ & -0.11 & 0.65 & -0.22 & 0.34 \\
\hline IVSd (cm) & +0.24 & 0.22 & +0.33 & 0.088 & +0.14 & 0.55 & +0.15 & 0.53 \\
\hline $\mathrm{AO}(\mathrm{cm})$ & +0.58 & 0.001 & +0.37 & 0.051 & +0.23 & 0.32 & +0.28 & 0.22 \\
\hline $\mathrm{LA}(\mathrm{cm})$ & +0.61 & 0.00055 & +0.20 & 0.32 & +0.39 & 0.079 & +0.46 & 0.037 \\
\hline LVEF (\%) & +0.21 & 0.29 & +0.15 & 0.46 & -0.49 & 0.025 & -0.54 & 0.012 \\
\hline \multirow[t]{3}{*}{ LVMI $\left(\mathrm{g} / \mathrm{m}^{2}\right)$} & +0.35 & 0.071 & +0.40 & 0.034 & +0.070 & 0.76 & +0.11 & 0.65 \\
\hline & \multicolumn{8}{|c|}{ ADPKD group $(n=47)$} \\
\hline & \multicolumn{4}{|c|}{ Females $(n=29)$} & \multicolumn{4}{|c|}{ Males $(\mathrm{n}=18)$} \\
\hline LVEDd $(\mathrm{cm})$ & +0.096 & 0.62 & +0.12 & 0.5 & +0.47 & 0.049 & +0.49 & 0.039 \\
\hline LVPWd $(\mathrm{cm})$ & +0.51 & 0.049 & +0.48 & 0.0084 & -0.25 & 0.31 & -0.099 & 0.70 \\
\hline $\operatorname{IVSd}(\mathrm{cm})$ & +0.67 & $<0.0001$ & +0.52 & 0.0038 & +0.30 & 0.23 & +0.43 & 0.072 \\
\hline $\mathrm{AO}(\mathrm{cm})$ & +0.52 & 0.0042 & +0.43 & 0.021 & +0.16 & 0.53 & +0.20 & 0.42 \\
\hline LA $(\mathrm{cm})$ & +0.31 & 0.096 & +0.31 & 0.11 & +0.41 & 0.090 & +0.34 & 0.17 \\
\hline LVEF (\%) & -0.15 & 0.43 & -0.12 & 0.56 & -0.33 & 0.18 & -0.44 & 0.065 \\
\hline $\operatorname{LVMI}\left(\mathrm{g} / \mathrm{m}^{2}\right)$ & +0.54 & 0.0027 & +0.50 & 0.0053 & +0.14 & 0.59 & +0.26 & 0.30 \\
\hline
\end{tabular}

LVEDd - left ventricular end-diastolic dimension ; LVPWd - left ventricular end-diastolic posterior wall dimension; IVSd - interventricular septal end-diastolic dimension; AO - aortic root dimension; LA - left atrium dimension; LVEF - left ventricular ejection fraction; LVMI left ventricular mass index; DBP - diastolic blood pressure; SBP - systolic blood pressure.

without LVH $(2.3 \pm 0.3$ vs $1.6 \pm 0.2 \mathrm{mg} / \mathrm{dL}, \mathrm{p}<0.05)$. The mean age of 116 ADPKD patients in this echocardiographic study was 41 years. Several other studies also showed a significant association between LVH and renal function in ADPKD patients [10]. Our ADPKD patients had serum creatinine concentrations of $0.84 \pm 0.18 \mathrm{mg} / \mathrm{dL}$ and did not differ in this respect from the control group.

Our results confirm the influence of HT on LVM in ADPKD patients with normal renal function which is more pronounced in females than males. However, it should be noted that lack of significance for some of the associations in male patients might primarily be due to the lower number of males compared to females. Other studies found increased LVM in ADPKD children and young adults in comparison to the general population [13-15]. Apparently, factors other than hemodynamics may be involved in this process, particularly during early stages of ADPKD.

Activation of systemic and local RAA systems with the effect of angiotensin II (AngII) and aldosterone on the cardiovascular system, electrolyte and water balance, and the central nervous system is listed among the major causes of LVH [22]. All components of the local RAA system are present in the heart, vascular wall, brain, fatty tissue, kidneys, and other organs. Experimental studies have demonstrated that AngII contributes to the progression of LVH in a way which is independent of its effect on blood pressure [23]. Elevated levels of AngII have been found in the cyst fluid of ADPKD patients. The angiotensin converting enzyme, AngII type 1 receptor, and AngII peptide have been demonstrated in the cysts and many tubules; some cyst fluids contain high AngII concentrations. Additionally, cystderived cells in culture continue to express the components of RAA at both the protein and mRNA levels [24]. According to some investigators, hyperactivity of intrarenal autocrine/ paracrine RAA in ADPKD is responsible for the continuous increase in AngII concentrations [25]. The HALT PKD study [12] confirmed that LVH can be reduced in hypertensive ADPKD patients treated with ACE inhibitors or AngII receptor blockers. It is known that the effects of AngII are mediated by the angiotensin receptor AT1 which generates phospholipid-derived second messengers leading to increased intracellular concentrations of ionized calcium and activation of several protein kinases such as protein kinase $C$, mitogen-activated protein kinase, and tyrosine-specific kinase [26]. 


\section{Kidney \\ Blood Pressure Research}

Kidney Blood Press Res 2012;36:301-309

\begin{tabular}{l|l}
\hline DOI: $10.1159 / 000343419$ & (C) 2012 S. Karger AG, Basel
\end{tabular}

Published online: December 12, 2012

www.karger.com/kbr

with LVM

Perturbations in normal intracellular $\mathrm{Ca}^{2+}$ concentrations underlie many common pathological conditions ranging from cardiac hypertrophy to ischemic death of neurons. Altered intracellular $\mathrm{Ca}^{2+}$ handling contributes importantly to impaired contractility associated with heart failure [27]. Impairment of intracellular $\mathrm{Ca}^{2+}$ homeostasis and mitochondrial function has been implicated in the development of LVH $[28,29]$. In our recent study [30] we have found that ADPKD patients with normal renal function had higher $\mathrm{Ca}^{2+}$ concentrations in serum and erythrocytes and higher serum PTH levels (borderline significance) compared with non-ADPKD controls. This may indicate that the natural course of ADPKD leads to disorders of calcium metabolism preceding the onset of renal failure. PKD1 and PKD2 gene products (PC-1 and PC-2 proteins) have been shown to assemble at the plasma membrane and to regulate calcium $\left(\mathrm{Ca}^{2+}\right)$ entry [31]. It is thought that renal epithelial cell hyperplasia in patients with ADPKD is a consequence of dysfunctional $\mathrm{Ca}^{2+}$ metabolism following mutations of polycystin proteins. A defect in $\mathrm{Ca}^{2+}$ binding mediated by mutations in polycystin proteins is a hypothetical factor contributing to left ventricular mass increase. Further studies are needed to elucidate the pathogenesis of organ involvement in ADPKD.

\section{Conclusions}

Left ventricular mass is increased in ADPKD females with normal renal function. This increase precedes loss of renal function and is associated with elevated blood pressure. A positive correlation between systolic and diastolic blood pressure and left ventricular mass index was found in ADPKD females but not in ADPKD males.

\section{Conflict of Interests}

The authors declare that there is no duality of interest associated with this manuscript.

\section{References}

1 Iglesias CG, Torres VE, Offord KP, Holley KE, Beard CM, Kurland LT: Epidemiology of adult polycystic kidney disease, Olmsted County, Minnesota: 1935-1980. Am J Kidney Dis 1983;2:630-639.

-2 Zeier M, Jones E, Ritz E: Autosomal dominant polycystic kidney disease-the patient on renal replacement therapy. Nephrol Dial Transplant 1996;11(S6):18-20.

-3 Pirson Y: Extrarenal manifestations of autosomal dominant polycystic kidney disease. Adv Chronic Kidney Dis 2010;17:173-180.

-4 Ecder T, Schrier RW: Hypertension in autosomal-dominant polycystic kidney disease: early occurrence and unique aspects. J Am Soc Nephrol 2001;12:194-200.

5 Schrier RW, Johnson AM, Mc Fann K, Chapman AB: The role of parental hypertension in the frequency and age of diagnosis of hypertension in offspring with autosomal-dominant polycystic kidney disease. Kidney Int 2003;64:1792-1799.

6 de Almeida EA, de Oliveira EI, Lopes JA, Almeida AG, Lopes MG, Prata MM: Ambulatory blood pressure measurement in young normotensive patients with autosomal dominant polycystic kidney disease. Rev Port Cardiol 2007;26:235-243.

-7 Valero FA, Martinez-Vea A, Bardaji A, Gutierrez C, Garcia C, Richart C, Oliver JA : ABPM and left ventricular mass in normotensive patients with autosomal dominant polycystic kidney disease. J Am Soc Nephrol 1999,10:1020-1026.

-8 Martinez-Vea A, Valero FA, Bardaji A, Gutierrez C, Broch M, Garcia C, Richart C, Oliver JA: Left ventricular hypertrophy in hypertensive patients with autosomal dominant polycystic kidney disease: influence of blood pressure and humoral and neurohormonal factors. Am J Nephrol 2000;20:193-200.

9 Chapman AB, Johnson AM, Rainquet S, Hossack K, Gabow P, Schrier R: Left ventricular hypertrophy in autosomal dominant polycystic kidney disease. J Am Soc Nephrol 1997;8:1292-1297. 


\section{Kidney \\ Blood Pressure Research}

Kidney Blood Press Res 2012;36:301-309

\begin{tabular}{l|l}
\hline DOI: 10.1159/000343419 & C 2012 S. Karger AG, Basel
\end{tabular}

Published online: December 12, 2012

www.karger.com/kbr

Pietrzak-Nowacka/Safranow/Czechowska et al.: ADPKD and Hypertension are Associated with LVM

10 Martinez-Vea A, Bardaji A, Gutierrez G, Garcia C, Peralta C, Aguilera J, Sanchez P, Vidiella J, Angelet P, Compte T, Richart C, Oliver JA: Echocardiographic evaluation in patients with autosomal dominant polycystic kidney disease and end-stage renal disease. Am J Kidney Dis 1999;34:264-272.

11 Bardaji A, Martinez-Vea A: Cardiac involvement in ADPKD: a hypertensive heart disease. Clin Nephrol 2001;56:211-220.

12 Perrone RD, Abebe KZ, Schrier RW, Chapman AB, Torres VE, Bost J, Kaya D, Miskulin DC, Steinman TI, Braun W, Winklhofer FT, Hogan MC, Rahbari-Oskoui F, Kelleher C, Masuomi A, Glockner J, Halin NJ, Martin D, Remer E, Patel N, Pedrosa I, Wetzel LH, Thompson PA, Miller JP, Meyers CM, Bae KT, HALT PKD Study Group: Cardiac Magnetic Resonance Assessment of Left Ventricular Mass in Autosomal Dominant Polycystic Kidney Disease. Clin J Am Soc Nephrol 2011;6:2508-2515.

13 Ecder T, Schrier RW: Cardiovascular abnormalities in autosomal dominant polycystic kidney disease. Nat Rev Nephrol 2009:5:221-228.

14 Bardaji A, Martinez-Vea A, Gutierrez C, Ridao C, Richart C, Oliver JA: Left ventricular mass and diastolic function in normotensive young adults with autosomal dominant polycystic kidney disease. Am J Kidney Dis 1998;32:970-975.

15 Martinez-Vea A, Bardaji A, Gutierrez C, Garcia C, Peralta C, Marcas L, Oliver JA: Exercise blood pressure, cardiac structure, and diastolic function in young normotensive patients with polycystic kidney disease: a prehypertensive state. Am J Kidney Dis 2004;44:216-223.

-16 Ravine D, Gibson RN, Walker RG, Sheffield LJ, Kincaid-Smith P, Danks DM: Evaluation of ultrasonographic diagnostic criteria for autosomal dominant polycystic kidney disease 1. Lancet 1994;343:824-827.

17 Levey AS, Stevens LA, Schmid CH, Zhang YL, Castro AF 3rd, Feldman HI, Kusek JW, Eggers P, Van Lente F, Green T, Coresh J, CKD-EPI (Chronic Kidney Disease Epidemiological Collaboration): A New Equation to Estimate Glomerular Filtration Rate. Ann Intern Med 2009; 150:604-612.

18 Lentner C: Geigy scientific tables. Vol. 5. Ciba Geigy Company, Basel 1990.

19 Tandler J: Anatomie des Herzens. Gustav Fischer Verlag, Jena 1913.

-20 Morgan HE, Baker KM: Cardiac hypertrophy. Mechanical, neural, and endocrine dependence. Circulation 1991;83:13-25.

-21 Levy D, Anderson KM, Savage DD, Kannel WB, Christiansen JC, Castelli WP: Echocardiographically detected left ventricular hypertrophy, prevalence and risk factors. The Framingham Heart Study. An Intern Med 1988;108:7-13.

-22 Schrier RW: Renal volume, renin-angiotensin-aldosterone system, hypertension, and left ventricular hypertrophy in patients with autosomal dominant polycystic kidney disease. J Am Soc Nephrol 2009;20:1888-1893.

23 Huggins CE, Domenighetti AA, Pedrazzini T, Pepe S, Delbridge LM: Elevated intracardiac angiotensin II leads to cardiac hypertrophy and mechanical dysfunction in normotensive mice. J Renin Angiotensin Aldosterone Syst 2003;4:186-190.

-24 Loghman-Adham M, Soto CE, Inagami T, Cassis L: The intrarenal renin-angiotensin system in autosomal dominant polycystic kidney disease. Am J Physiol Renal Physiol 2004;287:F775-F788.

25 Sadoshima J, Izumo S: Molecular characterization of angiotensin II-induced hypertrophy of cardiac myocytes and hyperplasia of cardiac fibroblasts. Circ Res 1993;73:413-423.

26 Huckle WR, Prokop CA, Dy RC, Herman B, Earp S: Angiotensin II stimulates protein-tyrosine phosphorylation in a calcium-dependent manner. Mol Cell Biol 1990;10:6290-6298.

27 Chakraborti S, Das S, Kar P, Samanta K, Kolley S, Ghosh S, Roy S, Chakraborti T: Calcium signaling phenomena in heart diseases: a perspective. Mol Cell Biochem 2007;298:1-40.

-28 Kieć-Wilk B, Petkow-Dimitrow P, Kwaśniak M, Dembińska-Kieć A: Role of impaired calcium homeostasis in the development of cardiac hypertrophy. Kardiol Pol 2009;67:1396-1402.

29 Diaz ME, Graham HK, Trafford AW: Enhanced sarcolemmal Ca2+ efflux reduces sarcoplasmic reticulum $\mathrm{Ca} 2+$ content and systolic Ca2+ in cardiac hypertrophy. Cardiovasc Res 2004;62:538-547.

30 Pietrzak-Nowacka M, Safranow K, Bober J, Olszewska M, Birkenfeld B, Nowosiad M, Ciechanowski K: Calcium-phosphate metabolism parameters and erythrocyte Ca2+ concentration in autosomal dominant polycystic kidney disease patients with normal renal function. Arch Med Sci 2012; DOI: 10.5114/ aoms.2012.30834.

31 Hanaoka K, Qian F, Boletta A, Bhunia AK, Piontek K, Tsiokas L, Sukhatme VP, Guggino WB, Germino GG: Coassembly of polycystin-1 and -2 produces unique cation-permeable currents. Nature 2000;408:990-994. 